\title{
Por uma postura decolonial na formação docente e na educação linguística: conversa com Tânia Rezende
}

\author{
Tânia Ferreira Rezende ${ }^{l}$ \\ Viviane Pires Viana Silvestre ${ }^{2}$ \\ Rosane Rocha Pessoa ${ }^{3}$ \\ Barbra Sabota ${ }^{4}$ \\ Valéria Rosa da Silva \\ Laryssa Paulino de Queiroz Sousa ${ }^{6}$
}

\section{Tânia Ferreira Rezende: lugar de existência}

Nascida em Barro Alto, uma pequena cidade no interior de Goiás, mais rural que urbana até o início dos anos 2000, quando lá se instala a Anglo-América. Uma cidade baixa, cercada por serras, mais perto de Brasília que de Goiânia, cheia de mistérios e histórias. Quando entrei para a escola, havia só um grupo, o Guaraciaba Augusta da Silva, todo mundo, ricas/os, pobres, negras/os, brancas/os, todas/os, estudavam juntas/os, no grupo escolar. No início, a diretora era uma mulher negra; jamais me esquecerei de seu cuidado comigo. Suas filhas, negras, eram professoras. Para mim, portanto, a convivência com mulheres negras professoras foi cotidiana, desde o início da escolarização. Havia problemas de aceitação, sim, com outras/os professoras/es e com todas/os as/os colegas que não eram parentes. Depois, quando chegaram as freiras e os médicos, os problemas se acirraram. No ensino médio, já em Goianésia, no Colégio Estadual Jales Machado, percebi, de chegada, um estranhamento. Não havia negras/os, nem mesmo pardas/os. O colégio era dirigido por freiras e algumas delas

1 Doutora em Estudos Linguísticos pela Universidade Federal de Minas Gerais (UFMG). Professora associada do Departamento de Linguística e Língua Portuguesa da Faculdade de Letras e do Programa de Pós-Graduação em Letras e Linguística da Universidade Federal de Goiás (UFG), Goiânia, Goiás. taferez@ufg.br

2 Doutora em Letras e Linguística pela Universidade Federal de Goiás (UFG), com estágio de pós-doutoramento no mesmo programa. Professora do curso de Letras: Português e Inglês e do Programa de Pós-Graduação Interdisciplinar em Educação, Linguagem e Tecnologias da Universidade Estadual de Goiás (UEG), Anápolis, Goiás.vivianepvs@gmail.com

3 Doutora em Linguística Aplicada pela Universidade Federal de Minas Gerais (UFMG), com estágio de pós-doutoramento pela Universidade de São Paulo (USP). Professora titular do Programa de Pós-Graduação em Letras e Linguística da Universidade Federal de Goiás (UFG), Goiânia, Goiás. Bolsista de Produtividade em Pesquisa (CNPq). E-mail: pessoarosane@gmail.com

4 Doutora em Letras e Linguística pela Universidade Federal de Goiás (UFG), com estágio de pós-doutoramento pela Universidade de Brasília (UnB). Professora do curso de Letras: Português e Inglês e do Programa de Pós-Graduação Interdisciplinar em Educação, Linguagem e Tecnologias da Universidade Estadual de Goiás (UEG), Anápolis, Goiás. Email: barbrasabota@gmail.com

5 Doutoranda do Programa de Pós-Graduação em Letras e Linguística da Universidade Federal de Goiás (UFG), Goiânia, Goiás. Professora do curso de Licenciatura Português/Inglês da Universidade Estadual de Goiás (UEG), Inhumas, Goiás, Brasil. valeriarosa.vr@gmail.com

6 Doutoranda do Programa de Pós-Graduação em Letras e Linguística da Universidade Federal de Goiás (UFG), Goiânia, Goiás. Bolsista Capes. laryssa.paulino1@gmail.com

Gláuks: Revista de Letras e Artes - jan/jun. 2020 - Vol. 20, $N^{\circ} 1$ 
eram estrangeiras. Eu ainda tinha muita dificuldade com o português, embora o professor me elogiasse, e tive de enfrentar o português estrangeiro, com sotaque. Definitivamente, meu ouvido não era meu amigo, não me ajudava. Eu preferia as aulas de inglês. Nesse período, percebi que o português da/o outra/o, se fosse com sotaque da/o estrangeira/o e se essa/e outra/o tivesse pele, cabelos e olhos claros, não era "português errado" ou "mal falado" e ninguém ria da fala dessa/e outra/o. Eu percebi que "sotaque feio" e "português errado" eram só para quem nasce no Brasil e não tem "corpo bonito". As freiras eram o modelo de perfeição em todos os sentidos. Naquele primeiro ano do ensino médio, eu estava com 16 anos, e meu pai fez a passagem, abruptamente. As freiras quiseram que eu fizesse o vocacional. Mesmo enlouquecida de dor, fragilizada e convencida de que as freiras eram o modelo de perfeição, recusei a caridade. Eu sabia que ainda que me tornasse freira, jamais seria uma freira. Segui. Desde a sétima série, havia decidido que queria cursar Letras, devido à minha paixão pela Literatura. Fiz Letras... Numa instituição evangélica. As escolas eram sempre cristãs, ou eram católicas ou eram evangélicas; depois, muito depois, soube que havia escola espírita, kardecista, logo, cristã. Fiquei curiosa com isso. Na faculdade, novamente, tive uma professora negra, professora de português, e nos demos muito bem. Participei de um concurso de poesia, venci, fui a primeira colocada. Foi um escândalo! Quando o escritor Bernardo Elis lá esteve para fazer uma conferência, eu fiz sua apresentação; despertei revolta na única colega barroaltense da instituição. No dia seguinte, ela me humilhou muito no jornal da faculdade. Depois, com tudo que foi acontecendo, descobri que não poderia ser escritora nem professora de literatura, porque as poucas escritoras que li durante a graduação e as colegas que tinha nas turmas eram tão modelo de perfeição quanto as freiras que dirigiam o colégio onde estudei. Então, no mestrado, mudei totalmente meu caminho. Decidi me dedicar à Linguística e, quando conheci a professora que viria a ser a orientadora da minha pesquisa, me apaixonei pela Sociolinguística e me senti me reconectando com a minha ancestralidade. E foi assim, fiz o mestrado na UFG com um estudo de Etnolinguística com um povo quilombola, pesquisa que ampliei no doutorado. Meu encontro com as/os indígenas no curso de Educação Intercultural da UFG, principalmente, com as/os Tapuias e as/os A'uwẽ, foi um encontro entre tempos e lugares atravessados por epifanias. Nesses encontros, encontros de almas, pude reunir meus pedaços, que se soltaram ao logo do tempo e estavam perdidos em diferentes lugares, e pude remendá-los, com afeto e conforto. Por isso, agora, eu entendo que diáspora, desprendendo um pouco das teorizações, todas importantes e pertinentes, é um acontecimento que reverbera de uma vida para outra ou acontece de forma simbólica e psicológica. Eu vejo a diáspora afetar a alma; é como quando o vento sopra na paineira e faz soltar a paina no ar. É assim, a vida bate na alma e faz soltar pedaços de sentimentos que ficam flanando pelo tempo-espaço, esperando encontrar a alma novamente. Foi assim comigo

Gláuks: Revista de Letras e Artes - jan/jun. 2020 - Vol. 20, $N^{o} 1$ 
quando encontrei a Sociolinguística e quando encontrei as/os indígenas, minhas painassentimentos, os pedaços da minha alma que estavam soltos, perdidos no tempo-espaço, me reencontraram e se reconectaram à minha alma. Eu voltei ao meu eixo, ao meu lugar de existência, a Barro Alto e ao Guaraciaba, ainda que não tenha voltado, ainda que esteja na UFG.

\section{O começo da conversa}

Em novembro de 2019, o Grupo de Estudos Transição, ligado aos Grupos de Pesquisa do Diretório do CNPq Formação de Professoras/es de Línguas e Rede Cerrado de Formação Crítica de Linguas, promoveu uma roda de conversa com a Profa. Tânia Ferreira Rezende, que contou com a presença de membros do Obiah: Grupo de Estudos Interculturais Decoloniais da Linguagem. A conversa teve duração de três horas, mas aqui trazemos um recorte das discussões referentes à formação docente e à educação linguística. A proposta da roda de conversa foi motivada pelas problematizações sobre decolonialidade construídas por Tânia Rezende em diferentes espaços - acadêmicos ou não - no Centro-Oeste brasileiro. Tais problematizações têm fomentado novas indagações e desestabilizações para nossas práticas formativas no âmbito da Linguística Aplicada Crítica, que gostaríamos de ver ecoadas no restante do Brasil.

Tânia: Quero agradecer a promoção desta conversa, porque já abre um espaço diferente. Promover esta conversa é promover formação, porque modificamos um pouco o que entendemos por formação.

Grupo Transição: Nós que agradecemos. Vamos começar. No texto Os compromissos da Sociolinguística, você afirma que "[m]uitos dos estudos que se declaram decoloniais, na realidade, tomam a colonialidade como contexto sócio-histórico de justificação e 
embasamento da discussão, porque tematizam as categorias herdadas ao colonialismo: raça/cor/etnia, gênero/sexualidade e classe/índices de massificação e seus derivativos, interseccionalizadas ou não. Nessa tematização, reafirmam muitos dos valores coloniais, por manterem, sem o perceber, concepções, posturas e atitudes do colonialismo" (REZENDE, 2019b, p. 2). Pensamos que muitos valores são mantidos na formação de professoras/es de língua inglesa, a começar pela língua que ensinamos (inglês) e pelo ensino da norma padrão, passando pelas instituições coloniais com que trabalhamos (universidade e escola) e terminando com a própria ideia do que é formar professoras/es. Como ser decolonial nesse contexto?

Tânia: Bem, a formação de inglês não é meu lócus. Eu trabalho com formação em língua portuguesa, então eu posso discutir de forma mais ampla a formação, e não especificamente a de inglês. Aqui, neste território, o inglês é ensinado como língua estrangeira e o português eu nem sei mais o que é. Eu fiz o estágio de inglês, dei aula de inglês, mas isso durou muito pouco. Eu fui para o português e não voltei mais para o inglês, mas vamos pensar a questão do que seja a formação. Corpo, território, língua e cultura são indissociáveis. A primeira questão que devemos ter em mente é essa indissociabilidade. Outra questão é que a formação no Brasil, em qualquer língua, em qualquer disciplina, me parece ser um projeto de produção do fracasso escolar. Eu me apoio muito em Maria Helena Souza Patto (2015) [mostrando o livro A produção do fracasso escolar: histórias de submissão e rebeldia]. Por que eu digo isso? Estou pensando na escola pública, que tem um projeto de política pública. E aí vamos para o ponto que vocês levantam nessa pergunta, que é a questão do colonialismo, da colonização, da colonialidade e da decolonialidade. Nós estamos discutindo muito mais decolonialidade do que colonialidade, sem conhecer o que foi a colonização. Todas/os querem promover a decolonialidade, enfrentando a colonialidade, mas sem a preocupação de conhecer o que foi a colonização do Brasil. E qual foi o papel da educação nesse projeto de colonização? A educação no Brasil e na América colonizada começa sobre duas estruturas: a religião e a força militar. Quem começa a escola nesses países? Os padres e os militares. E 
isso forma consciência, que depois fica no inconsciente coletivo. Quando pensamos em educação, mesmo sem perceber, pensamos na igreja e no quartel. Aldeias, aldeamentos, escolas jesuíticas, missões, reduções... é assim que começa a educação. Isso está no imaginário. Por que as pessoas querem tanto os colégios militares, a militarização das escolas? A educação está ancorada na religião e na escola militarizada. De outro lado, o que nós temos? Uma desqualificação social da profissão docente, sobretudo depois que alguns corpos passaram a ocupar esse espaço. Vamos pensar quais são esses corpos que estão nas licenciaturas. Quem são essas pessoas? Então, vamos juntar esses dois pontos e pensar: como fazer uma formação docente que respeite a humanidade dessa pessoa que está se formando e, ao mesmo tempo, que a forme sem imposição? Isso nos leva ao conceito de formação como ensino que está em Patto (2015). Como é que começa o ensino? Eu ainda estou discutindo a colonização, porque não dá para falar de decolonialidade, nem de colonialidade, sem antes entender o que foi a colonização. O que é o ensino? O ensino chega como a capacidade, a competência de uma pessoa que sabe para moldar uma pessoa que não sabe. $\mathrm{O}$ padre e o militar são os detentores do conhecimento. O conhecimento é único. Ele não está neste território. O território colonizado não tem conhecimento. O conhecimento vem de fora, de um lócus de poder, que é a Europa, por uma voz de poder, e esse conhecimento é transmitido, é ensinado para quem não sabe. A ideologia colonial, que ainda reproduzimos, é que a pessoa chega na escola despossuída de saber e sai da escola uma sábia. Como isso não é uma mágica, começa esse grande projeto de produção do fracasso escolar, porque, nisso, há uma barreira que é interligada: língua e epistemologia. Essa barreira é muito forte. A/O aluna/o está em um território de línguas que não são as línguas do conhecimento que é ensinado e de epistemologias que não são as epistemologias do conhecimento que é ensinado, e isso é desconsiderado. Há uma língua sagrada, que é o latim; há uma língua de sabedoria, que é o grego; e há uma língua de cultura, que é a língua portuguesa. São três línguas na escola. E o jesuíta aprende a língua do "autóctone", do "gentio" - o tupi -, que é para facilitar a dominação. Eram cerca de 1500 línguas, talvez aparentadas, que foram postas como uma língua só (e aqui, mobilizo outra ideologia colonial: a classificação e a catalogação das

Gláuks: Revista de Letras e Artes - jan/jun. 2020 - Vol. 20, $N^{o} 1$ 
línguas). É como se disséssemos que o italiano, o português e o catalão são uma única língua. Assim, Anchieta faz a gramática da "língua mais falada da costa do Brasil", gramática da língua, uma língua só, desconsiderando que eram muitas línguas. Ele catequiza e ensina essas/ es índias/os nessa língua. Não tem como dar certo! Então, o ensino e a formação, neste território, têm um peso ideológico da transmissão de um saber de cultura a um povo despossuído de cultura. Isso é um entendimento do que foi a colonização e de como essa colonização permanece no que nós estamos chamando de colonialidade. Se nós não entendemos essas questões e se isso permanece em forma de ideologias dentro da educação, não é possível pensar em decolonialidade. Consequentemente, tudo que fazemos é tematizar. Não há um enfrentamento - porque a decolonialidade é um enfretamento das ideologias coloniais - se nós sequer entendemos quais são essas ideologias. Para mim, considerando meu lugar de existência, a decolonialidade não é uma teoria; é uma postura de enfrentamento que modifica a interpretação das teorias. Não dá para teorizar! Retomando a pergunta, "como ser decolonial nesse contexto?", ser decolonial não é para a nossa geração. Nós vamos trabalhar e temos de lutar muito para formar pessoas críticas que tenham condições de formar uma geração que seja coletivamente decolonial. Estamos numa formação muito entranhada pelo colonialismo. Quando falamos em decolonizar qualquer coisa, essa é uma postura colonial. Querer decolonizar é uma postura colonial. Entendem como é uma armadilha? Caímos nessa armadilha o tempo todo. Então, temos de lutar para que outras gerações vindouras consigam ter posturas realmente decoloniais. Nós temos a luta, e aí está o papel de uma formação democrática de docentes. A formação docente é um espaço dessa construção para outras gerações. Digo isso por quê? Para romper com essa angústia: “eu tenho de ser decolonial!”. É um trabalho, é uma trajetória, é coletivo e é processual. Vamos parar de sofrer com isso! Não sofra para ser, porque ser é muito essencialista. Assim, caímos na prática colonial de querer fazer ser. A nossa pressa, a nossa angústia nos torna colonizadoras/es. Sem entender a colonização, nós não vamos conseguir pensar uma formação docente que seja, no mínimo, democrática. Podemos parafrasear Paulo Freire (1974): ninguém decoloniza ninguém, porque estamos lidando com pessoas que têm vontade própria. Elas têm direito a ter sua vontade 
respeitada. Ou então, nossa postura é colonialista, autoritária. Ou seja, as pessoas se decolonizam em comunhão. A ideia é que a decolonialidade seja promovida coletivamente e não ensinada ou imposta. A linha é muito tênue, a fronteira é muito sutil. Atravessamos com rapidez, porque somos formadas/os nessa trajetória colonialista/autoritária. Então, dessa primeira problematização, o que eu quero dizer é isto: nem todo mundo que discute raça, cor, gênero, sexualidade, classe está discutindo decolonialmente; só está tematizando. Tematizar não é decolonizar, porque, às vezes, a postura na tematização não é de enfrentamento. Nem todas/os conseguem ter essa postura de enfrentamento - e não têm de ter, ou daqui a pouco, estamos querendo que todo mundo seja decolonial, e isso nos coloca nas caixinhas também. E caímos no modo combate sem perceber: "seja decolonial, ou vou te combater!". De forma geral, nessa primeira questão, é isso.

Viviane: Sobre essa questão de ser decolonial, temos trabalhado com o conceito de esforços decoloniais (SILVESTRE, 2016), entendendo que, de fato, não temos condições de ser ou de realizar uma formação plenamente decolonial. Temos trabalhado com esse conceito de esforço, mostrando que são tentativas. A Julma (BORELLI, 2018) discute o conceito de desafio decolonial. E é mesmo um desafio, por tudo o que você colocou, e, por isso, trabalhamos com essa perspectiva do esforço no estágio. São tentativas mesmo. São muitos enfrentamentos, mas o que eu tento é ressignificar minhas práticas como professora de estágio: a relação com a escola, com as/os professoras/es em formação, com as/os professoras/ es da escola; e as atividades que eu tento promover. Então, Tânia, você poderia falar um pouco dessa perspectiva de esforço?

Tânia: Viviane, eu penso assim, não são apenas os conhecimentos que você mobiliza, e sim sua postura - a forma como você se relaciona com o seu trabalho, com as/os estudantes de estágio, com as/os professoras/es da escola. Não estou falando de você, Viviane, professora de estágio, ponto, mas professora de estágio da Universidade Estadual de Goiás, atuando no interior de Goiás. Isso nos leva a Boaventura de Sousa Santos (2006), quando critica a razão 
metonímica - não podemos tomar uma parte pelo todo, não podemos generalizar uma parte como se fosse o todo. O que eu vejo muito é professoras/es de estágio trazerem impensadamente autoras/es que discutem estágio no âmbito nacional para a realidade de Goiás. Eu não estou criticando o trabalho dessas/es docentes, mas sim a aplicabilidade cega desses estudos ao estágio, que é sempre localizado. Quando Paulo Freire (1974) fala sobre práxis, uma prática que é ação, que é uma prática reflexiva, ele está falando de teorização. Por exemplo, não é uma teoria do sudeste brasileiro que dará conta de uma realidade escolar no interior de Goiás em que há estudantes Xavante que não falam português. É preciso teorizar a partir do lugar e com o lugar, sem ficar listando Quijano, Mignolo e Walsh automaticamente. Não se trata de dar as costas para quem veio antes, mas de, a partir de diálogos que estão aí, pensar que outros diálogos eu vou construir, com quem está junto comigo, a partir da minha realidade. Isso é uma postura decolonial. Sobre a questão da formação de professoras/es de inglês, em específico, ela é desafiadora por quê? Primeiro ponto: o status do inglês no mundo e, depois, o status do inglês no Brasil. Segundo ponto: a nossa relação com língua. Então, voltando ao que disse, no início da escolarização no Brasil, a pedagogização de língua foi de língua estrangeira. Nossa história de aprender língua na escola, no Brasil, é de aprender língua como língua estrangeira. Nossa experiência de aprender língua estrangeira como uma língua que violenta, que mata, está codificada em nosso inconsciente e precisamos trabalhar isso na formação de professoras/es de línguas. Estou falando de trazer a sócio-história da formação do Brasil para a formação de professoras/es de inglês, de espanhol, de português, de qualquer língua. Além disso, fazer uma roda de conversa com essas/es professoras/es em formação pode contribuir para que percebam de onde vem sua trava com o inglês e, assim, entendam a trava das/os alunas/os.

Barbra: Temos tentado trabalhar isso, Tânia, com as questões das narrativas que propomos nos diários. Pedimos às/aos alunas/os, professoras/es em formação, que escrevam a história delas/es com o inglês: como foi a história de aprendizagem, qual é a relação com a língua (quais os sonhos, as expectativas, as frustrações que têm com o inglês) para tentar 
desembaraçar isso que já trazem e que impede que pensem em outras formas de trabalhar o inglês. Tem sido interessante o trabalho com as narrativas, mas eu acho que ainda precisamos de outra coisa.

Tânia: No caso da formação do inglês, a narrativa tem de ser nas duas línguas: português e inglês. É preciso romper com essa cultura do monolinguismo: "se eu sou professora de inglês, eu vou falar só de inglês. Se eu sou professora de português, eu vou falar só de português". Às vezes a trava do inglês está na trajetória do português, tem a ver com a aprendizagem ou não da norma padrão no português. O nosso encontro histórico, conflituoso, violento se dá com a chegada do português. E é uma norma. Já chega normatizado, chega normatizando a sua cabeça, porque a normatização linguística é uma normatização de subjetividade. Não é só o que você fala ou escreve; é o que você pensa, é o que você sente, é como você vê o mundo. O ensino da norma padrão é: "você vai ver o mundo desse jeito, porque esse é o jeito correto de ver o mundo"; "você vai pensar assim, porque assim é a forma correta de pensar"; e "você vai sentir isso, porque esse é o sentimento correto. O resto é pecado". O sentimento de culpa vem com isso aí. Então, a trava no inglês, no espanhol pode estar no encontro com o português. Assim, precisamos também discutir sobre a posição da cultura monolinguista no Brasil. Eu gostei demais da tese da Viviane (SILVESTRE, 2016) nesse ponto também, porque ela faz o que eu chamo de travessia sociolinguística - trânsito e atravessamentos entre diferentes práticas sociolinguísticas, epistêmicas e culturais, em uma mesma língua ou entre línguas diferentes, pressupondo práticas de uma mesma língua (REZENDE; LIMA, no prelo). Essa travessia sociolinguística é importante, porque você está ensinando inglês para pessoas que pensam, sentem, sonham em português, que é a tese do José Baptista (em andamento) em Moçambique. Essa trajetória sociolinguística vem do português para o inglês. É importante provocar nas/os alunas/os a reflexão sobre como foi a vida linguística antes da escola; quando chega na escola; quando se encontra com o inglês. É nesse sentido que falo sobre superar essa nossa cultura monolíngue, de ver uma língua por vez. Um dia, um menino Tapirajá (TapirapéKarajá) de nove anos, mais ou menos, que falava tapirapé, karajá e português, me perguntou: 
“tia, que língua você fala?". Eu falei: "português". O menino: "não, as outras?”. Eu falei: “não, é só português". O menino: “e como é que você entende as pessoas?”. Ou seja, uma criança de nove anos, que fala três línguas, não entende como é que eu, com uma língua, consigo entender as pessoas. Temos de compreender isso, porque é uma realidade no Brasil, por exemplo, em Aragarças [Goiás]. A escola estadual em Aragarças está cheia de indígenas que não falam português, e as professoras não falam as línguas delas/es. Vão lá ver o que acontece e vocês ficarão felizes com seus probleminhas de inglês.

Grupo Transição: Como você entende os conceitos ouvir e escutar (REZENDE, 2017) nos contextos de sala de aula e de formação docente? Com base nesses conceitos e na perspectiva decolonial, você poderia compartilhar algumas de suas reflexões concernentes à relação entre docentes e discentes? Como lidar com as relações de poder?

Tânia: Relação de poder não é uma coisa fácil de lidar. Minha experiência com formação docente é na Licenciatura em Português, na Licenciatura Intercultural e no trabalho com professoras quilombolas. “Como lidar com as relações de poder?”. Acho que não é só uma questão de relações de poder, mas de relações humanas, com suas paixões e ideologias, geradas por e que geram as relações de poder. Antes de pensar nas relações de poder, é preciso ter um entendimento do que é dignidade humana, do que é humanidade e do que são direitos humanos. E essas pessoas todas com as quais eu trabalho têm noções diferentes disso. Nesse sentido, temos de trazer o Lynn Mário (MENEZES DE SOUSA, 2011a, 2011b) para a conversa também: é escutar as pessoas, mas eu me escutar escutando essas pessoas, porque eu estou também numa relação de poder comigo mesma. "Quem sou eu, professora universitária? Quem sou eu em todas as relações de poder em que eu estou implicada? E quando eu me escuto escutando, o que essa escuta faz com a minha subjetividade?". Uma coisa é a consciência política que temos, formada teoricamente. Outra coisa é a subjetividade, que vem sendo formada desde o útero e não é transformada tão facilmente. A consciência não cura as feridas da subjetividade. Então, ao me escutar escutando as pessoas, vejo o que está 


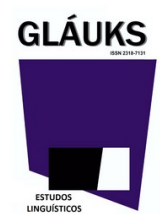

acontecendo com minha subjetividade. A consciência ouve mais do que escuta; a subjetividade escuta mais do que ouve [a diferença na descrição dos verbos ouvir e escutar é discutida na tese de Silva (2012)]. Assim, a relação de poder pode ser um escudo em defesa da subjetividade que surge quando essas feridas são muito profundas. Não podemos esquecer que as relações humanas antecedem às relações de poder, e que, na relação de poder, há uma relação entre subjetividade e consciência. Nossa consciência é transformada politicamente, mas nossa subjetividade permanece presa em uma supremacia masculina, branca, europeizada, porque esta é a formação de base. Essa é a grande "trama do crochê": direitos humanos, linguagem e relações de poder presentes na formação docente. E é por meio da formação que isso vai ou não para a sala de aula da educação básica. E isso é, inclusive, uma questão que pretendo pesquisar: "O que tem formado a subjetividade de crianças e adolescentes?”.

Grupo Transição: Em um cenário em que o projeto político educacional impulsiona a escola a demonstrar a inabilidade da/o brasileira/o para aprender, confirmando a América Latina como campo dos fracassos (aludindo à teoria do déficit) - temas recorrentes em seus textos (REZENDE, 2015, 2017, 2019a, 2019b) - que recomendações você tem para licenciandas/os e suas/seus professoras/es?

Tânia: Resistir! Eu acho que precisamos de ações como essa que fizemos aqui: sentar, conversar e pensar ações de resistência ao cenário atual. Não podemos nos isolar, é importante resistir coletivamente. Para pensar especificamente a área de inglês como língua estrangeira, recorro a uma experiência com as/os estudantes indígenas que estão estudando português aqui na Faculdade de Letras da UFG. Temos conversado sobre essas dificuldades de aprendizagem e como elas/es veem nossa prática pedagógica e, nesse sentido, penso que usar as narrativas - juntando o português e o inglês - pode fazer emergir muita coisa interessante. Em um projeto com as/os Xavante, solicitei que Amós, meu aluno Xavante, produzisse um texto em português. E ele assim o fez: produziu um texto em um português que

Gláuks: Revista de Letras e Artes - jan/jun. 2020 -Vol. 20, $N^{o} 1$ 
é de Xavante, e isso facilitou o acesso ao texto para outra/o Xavante. Ou seja, uma proposta seria a/o docente brasileira/o produzir uma narrativa em inglês para trabalhar com sua/seu aluna/o. Para nós, a narrativa é um lócus pedagógico, ou seja, é um lugar de aprendizagem. A narrativa é, para nós, o lócus de aprendizagem ancestral.

\section{Referências Bibliográficas}

BAPTISTA, José dos Santos. Paradigmas de educação, realidades e adversidades: o caso de formação de professores de ensino de Português. Tese em andamento (Doutoramento em Ciências da Linguagem Aplicadas ao Ensino de Línguas) - Faculdade de Ciências da Linguagem, Comunicação e Artes, Universidade Pedagógica de Maputo, Maputo, Moçambique, em andamento.

BORELLI, Julma Dalva Vilarinho Pereira. $O$ estágio e o desafio decolonial: (des)construindo sentidos sobre a formação de professores/as de inglês. 2018. 222f. Tese (Doutorado em Letras e Linguística) - Faculdade de Letras, Universidade Federal de Goiás, Goiânia, 2018.

FREIRE, Paulo. Pedagogia do oprimido. São Paulo: Paz e Terra, 1974.

MENEZES DE SOUZA, Lynn Mario Trindade. Para uma redefinição de letramento crítico: conflito e produção de significação. In: MACIEL, Ruberval Franco; ARAÚJO, Vanessa de Assis. (Org.). Formação de professores de línguas: ampliando perspectivas. Jundiaí: Paco Editorial, 2011a. p. 128-140.

MENEZES DE SOUZA, Lynn Mario Trindade. O professor de inglês e os letramentos no século XXI: métodos ou ética?. In: JORDÃO, Clarissa Menezes; MARTINEZ, Juliana Zeggio; HALU, Regina Célia. (Org.). Formação "desformatada": práticas com professores de língua inglesa. Campinas: Pontes Editores, 2011b. p. 279-303.

PATTO, Maria Helena Souza. A produção do fracasso escolar: histórias de submissão e rebeldia. 4. ed. São Paulo: Intermeios, 2015.

REZENDE, Tânia Ferreira. Políticas de apagamento linguístico em contexto brasileiro. In: BARROS, Débora Magalhães de; SILVA, Kleber Aparecido; CASSEB-GALVÃO, Vânia

Gláuks: Revista de Letras e Artes - jan/jun. 2020 -Vol. 20, $N^{o} 1$ 
Cristina. (Org.). O ensino em quatro atos: interculturalidade, tecnologia de informação, leitura e gramática. Campinas: Pontes, 2015. p. 63-77.

REZENDE, Tânia Ferreira. Posfácio. In: SILVESTRE, Viviane Pires Viana. Colaboração e crítica na formação de professores/as de línguas: teorizações construídas em uma experiência com o Pibid. Campinas: Pontes Editores, 2017. p. 279-289.

REZENDE, Tânia Ferreira. Como dialogar em meio à turbulência das lutas narrativas? Goiânia-GO: Obiah: Grupo de Estudos em Cosmolinguística, 2019a. p. 1-11. Manuscrito não publicado.

REZENDE, Tânia Ferreira. Os compromissos da Sociolinguística. Goiânia-GO: Obiah: Grupo de Estudos em Cosmolinguística, 2019b. p. 1-15. Manuscrito não publicado.

REZENDE, Tânia Ferreira; LIMA, Hildomar José de. Base Nacional Comum Curricular: diretrizes para a sustentação da colonialidade da linguagem. In: SILVA, Kleber Aparecido da; XAVIER, Rosely Perez. A Base Nacional Comum Curricular e o ensino de língua portuguesa. São Paulo: Pontes, no prelo.

SANTOS, Boaventura de Sousa. A gramática do tempo: para uma nova cultura política, para um novo senso comum. Porto: Afrontamentos, 2006.

SILVA, Leosmar Aparecido da. As bases corporais da gramática: um estudo sobre conceptualização e metaforização no português brasileiro. 2012. 284f. Tese (Doutorado em Letras e Linguística) - Faculdade de Letras, Universidade Federal de Goiás, Goiânia, 2012.

SILVESTRE, Viviane Pires Viana. Práticas problematizadoras e de(s)coloniais na formação de professores/as de línguas: teorizações construídas em uma experiência com o Pibid. 2016. 239f. Tese (Doutorado em Letras e Linguística) - Faculdade de Letras, Universidade Federal de Goiás, Goiânia, 2016. 